\title{
ARDS and ECMO, an update on critical care nursing
}

\author{
Audrey Courtin, Lucienne Sanchez, Jean-Claude Sinquet, Philippe Gaudard, Jacob Eliet, \\ Frédéric Barge, Pascal Colson
}

Department of Intensive Care, Hopital Arnaud de Villeneuve, Montpellier, France

Email: p-colson@chu-montpellier.fr

Received 18 September 2012; revised 20 October 2012; accepted 2 November 2012

\begin{abstract}
The acute respiratory distress syndrome (ARDS) is a very serious pathology caused by inflammation of the lung, usually infectious or traumatic. The alveoli are filled with inflammatory fluid, impairing gas exchange. Mechanical ventilation is the inevitable treatment, but it must ensure specific levels of alveolar pressure, tidal volume, and positive end-expiratory pressure (PEEP) not to exacerbate inflammation and ARDS. This is called protective ventilation but it does not always guarantee satisfactory blood gases, only the extra-corporeal membrane oxygenation (ECMO) can provide. Management of ARDS patient under ECMO is complex because it combines the care related to intensive care patient, very restrictive mechanical ventilation and ECMO. Intensive care nurse requires a very good knowledge of lung disease and respiratory assistance constraints, whether ventilatory or extra-corporeal.
\end{abstract}

Keywords: Acute Respiratory Distress Syndrome; ECMO

\section{INTRODUCTION}

The acute respiratory distress syndrome (ARDS) seriously attacks the pulmonary function and threatens life because lungs become incompetent and severe hypoxia develops $[1,2]$. Without respiratory support, the patient is unlikely to survive [3]. However, mechanical ventilation, which is "contra-physiological", can be deleterious in maintaining lung inflammation that characterizes the disease [4]. Yet, it is essential to ensure oxy-genation and $\mathrm{CO}_{2}$ removal of blood. So, strict ventilator settings should be respected to make it "protective". If haematosis is not provided in these conditions, extra-corporeal oxygenation (ECMO) takes over, allowing the lungs to recover. These techniques require nurses a thorough knowledge of the pathology and treatment issues: protecting the lung and ensuring haematosis until recovery. This knowledge has substantially evolved over the last
20 years $[5,6]$.

\section{ARDS, A TERRIBLE CONDITION}

ARDS is a very serious condition with a high mortality $(20 \%-40 \%)$ [3]. It is caused by inflammation of the lung developing quite rapidly (less than 72 hours), characterized by bilateral opacities visible on chest X-ray without signs of heart failure (pulmonary edema) [1,7]. Severe hypoxia refractory to high oxygen supply develops $\left(\mathrm{PaO}_{2} / \mathrm{FiO}_{2}<200 \mathrm{mmHg}\right)$. The inflammation is usually reversible, but pulmonary fibrosis scarring may occur, responsible for severe sequelae with definitive respiratory disability [8].

\subsection{ARDS Clinical Presentation}

The ARDS is defined as an acute respiratory failure, cyanosis refractory to oxygen therapy, and diffuse infiltrates evident on the chest radiograph. It is often progressive, characterized by distinct stages with different clinical and radiographic manifestations. The acute, or exudative, phase is manifested by the rapid onset of respiratory failure. Arterial hypoxemia that is refractory to treatment with supplemental oxygen is a characteristic feature. Radiographically, the findings are indistinguishable from those of cardiogenic pulmonary edema with alveolar infiltrates. Bilateral infiltrates may be patchy or asymmetric and may include pleural effusions. Computed tomographic scanning has demonstrated that alveolar filling consolidation, and atelectasis occur predominantly in dependent lung zones, while other areas may be relatively spared. However, bronchoalveolar lavage studies indicate that even radiographically spared, nondependent areas may have substantial inflammation.

Pathological findings include diffuse alveolar damage, with neutrophils, macrophages, erythrocytes, hyaline membranes, and protein rich edema fluid in the alveolar space, capillary injury, and disruption of the alveolar epithelium.

Although the ARDS may resolve completely in some patients after the acute phase, in others it progresses to fibrosing alveolitis with persistent hypoxemia, increased 
alveolar dead space, and a further decrease in pulmonary compliance.

The recovery phase is characterized by the gradual resolution of hypoxemia and improved lung compliance. Typically, the radiographic abnormalities resolve completely. The degree of histologic resolution of fibrosis has not been well characterized, although in many patients pulmonary function returns to normal [2].

\subsection{ARDS Pathogenesis}

Two separate barriers form the alveolar-capillary barrier, the microvascular endothelium and the alveolar epithelium. The acute phase of acute lung injury and the ARDS is characterized by the influx of protein-rich edema fluid into the air spaces as a consequence of increased permeability of the alveolar-capillary barrier [2].

The inflammatory pulmonary edema is due to direct (infection, inhalation, trauma...) or indirect (systemic inflammation, polytransfusion, extracorporeal circulation for cardiac surgery...) injury of the lung [1,2,7].

The alveoli are filled with inflammatory fluid, causing gas exchange impairment. These soaked alveoli compress healthy adjacent areas, favoring alveolar collapse, creating non-ventilated zones (derecruitment). In addition, the degradation of surfactant, which lines the walls of the alveoli usually, preventing their closure during expiration, may increase this phenomenon $[1,2,7]$.

The inflammatory infiltration increases weight of the lung. It loses its elastic properties and becomes difficult to inflate; its compliance falls.

The surface of the alveoli available for gas exchange in the lungs is decreased in some areas, and then becomes insufficient to ensure complete haematosis, causing hypoxemia. Similarly, the $\mathrm{CO}_{2}$ is difficult to remove, resulting in hypercapnia and respiratory acidosis. To maintain satisfactory oxygenation and normocapnia, physiological ventilation is strongly stimulated, but is ineffective or quickly exhausting. Relay with mechanical ventilation is unavoidable, even though it carries a risk of worsening inflammation.

\section{EFFECTIVE TREATMENT OF ARDS}

The cornerstone of the management of ARDS is treatment of the precipitating illness (infection treatment for instance), and application of a low-volume, low-pressure ventilation strategy. The use of a conservative fluid-management strategy is also recommended and the administration of neuromuscular blocking agents may be associated with decreased mortality when they are used early in the course of severe ARDS [9,10].

In patients with refractory gas-exchange abnormalities despite these measures, other so-called unproven therapies should be considered. These include glucocorticoids, inhaled vasodilators (N0), lung recruitment maneuvers, high levels of PEEP, prone positioning, and high-frequency oscillatory ventilation.

The decision to use such therapies, including ECMO, and the order in which they are used, depend on the clinician's preference and the availability of resources, including access to referral centers, since evidence-based algorithms are not available yet.

\subsection{Mechanical Ventilation Can Worsen ARDS}

Mechanical ventilation is essential in severe ARDS but dangerous.

Physiological ventilation is intended to carry air to the alveoli through a bronchial increasingly ramified circuit. During inhalation, the diaphragm moves down, creating a vacuum in the lungs which sucks the air inside the bronchial tree to the alveoli. The rib cage expands and the lungs, secured to the chest wall by the pleura, fill with air. The expiration is passive. The thorax returns to its initial position by releasing the elastic diaphragm and chest. Pressure becomes positive, the air is expelled. It is therefore a respiratory cycle at very low pulmonary pressures (Figure 1).

Many things change during mechanical ventilation. It is contra physiological, since the respiratory cycle is in positive pressure, either during insufflation and expiration. Moreover, mechanical ventilation may induce lung injury, by excess of volume inflated (volotrauma) or by excessive pressure (barotrauma) [10,11]. It has been shown experimentally that in a few minutes, mechanical ventilation may cause inflammatory destruction of the alveoli [12]. These lesions are favored by their overdistention and deflation. Especially, the sequence of both activates the inflammatory process and alters the surfactant. The overdistention can be avoided by reducing the volume inflated (tidal volume) and intra alveolar pressure. Maintaining a positive pressure at the end of expiration (PEEP) prevents deflation and therefore alveolar collapse, which causes loss of functional alveoli (derecruitment) [13].

Alveoli affected by inflammation are excluded from ventilation; normal tidal volume (8 to $10 \mathrm{ml} / \mathrm{Kg}$ ) can generate very high pressures in areas where alveoli are healthy or mildly affected. To avoid this complication, special attention should be paid to the plateau pressure at the end of insufflation, which represents the alveolar pressure (Figure 2). The goal of mechanical ventilation is to ensure haematosis, limiting the risks of trauma with appropriate ventilator settings.

\subsection{Is There a Protective Mechanical Ventilation?}

This concept was originally introduced in the context of ARDS, because the extremely serious pulmonary damage 


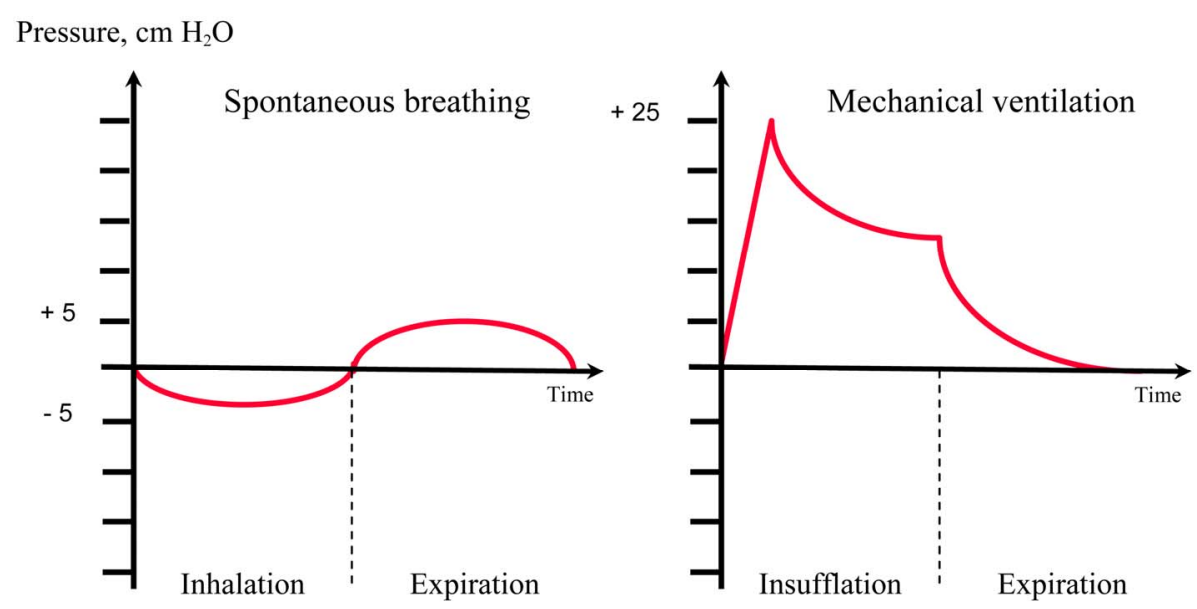

Figure 1. Changes in intrathoracic pressure during spontaneous breathing and mechanical ventilation.

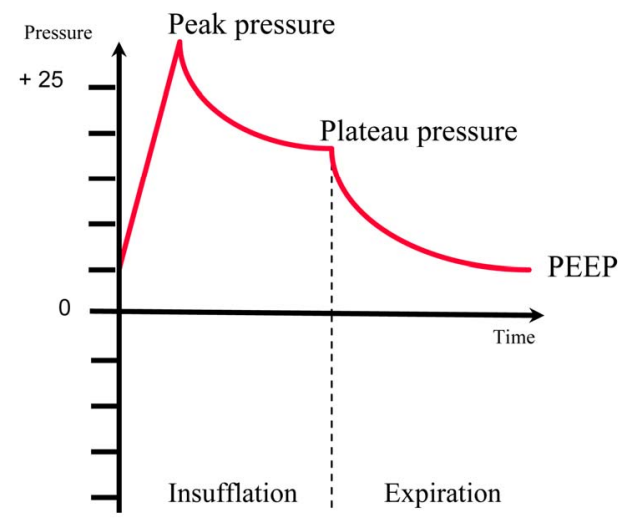

Figure 2. Respiratory cycle during mechanical ventilation.

of this disease imposes drastic respiratory conditions as not to aggravate the inflammation, but it tends to extend to any mode of ventilation $[12,13]$.

The principle of this is to protect alveoli and avoid the derecruitment.

We are talking about protective ventilation when to limit intra alveolar pressure (plateau pressure $<30 \mathrm{~cm}$ $\mathrm{H}_{2} \mathrm{O}$ ), tidal volume is reduced to a minimum $(6-8 \mathrm{ml} / \mathrm{kg})$ (Table 1).

Sometimes, this leads to ventilator regime having to tolerate acceptable hypercapnia if the acidosis is moderate $(\mathrm{pH}>7.20)$. The alveolar derecruitment is avoided by maintaining a high PEEP (8 to $15 \mathrm{~cm} \mathrm{H}_{2} \mathrm{O}$ ) [13-15].

If despite these conditions of mechanical ventilation, possibly associated with adjuvant techniques (sedation, muscle relaxation, prone position, NO inhalation), the blood gases are not good enough $\left(\mathrm{SpO}_{2}<90 \%\right.$, hypercapnia with $\mathrm{pH}<7.20$ ), the use of extracorporeal membrane oxygenation (ECMO) is considered because increasing tidal volume or plateau pressure would be to the detriment of healthy areas that would suffer volo or
Table 1. Criteria for protective mechanical ventilation.

\begin{tabular}{ccc}
\hline & $\begin{array}{c}\text { Mechanical } \\
\text { ventilation only }\end{array}$ & $\begin{array}{c}\text { Mechanical } \\
\text { ventilation and ECMO }\end{array}$ \\
\hline Tidal volume & 6 to $8 \mathrm{ml} / \mathrm{kg}^{*}$ & $<6 \mathrm{ml} / \mathrm{kg}^{*}$ \\
Plateau pressure & $<30 \mathrm{~cm} \mathrm{H}_{2} \mathrm{O}$ & $<28 \mathrm{~cm} \mathrm{H} \mathrm{H}_{2} \mathrm{O}$ \\
PEEP & $8-15 \mathrm{~cm} \mathrm{H}_{2} \mathrm{O}$ & $8-15 \mathrm{~cm} \mathrm{H}_{2} \mathrm{O}$ \\
\hline
\end{tabular}

"Ideal weight or predicted. Rating: Male: height in cm-100, Female: height in $\mathrm{cm}-110$.

barotrauma. The earliness of its implantation can be decisive for the vital prognosis [16-18].

\section{ECMO, PULMONARY LAST RESORT OR EXTREME PROTECTION?}

ECMO circuit includes a blood pump, a membrane lung, and conduit tubing. Depending on the application additional components may include a heat exchanger, monitors and alarms (Figure 3) [19].

The membrane mimics and replaces the pulmonary alveolar membrane. It thus allows oxygenating the blood and purifying it of $\mathrm{CO}_{2}$. The most common technique is the veno-venous ECMO where an extracorporeal circuit is connected in parallel to the patient's circulation on the venous return with two main options, femoral-femoral, or jugular-femoral (more difficult to implant).

\subsection{ECMO Circuit}

The pump should be able to provide full blood flow for the patient, i.e. blood flow $3 \mathrm{~L} / \mathrm{m}^{2} / \mathrm{min}$ (neonates 100 $\mathrm{cc} / \mathrm{kg} / \mathrm{min}$; pediatrics $80 \mathrm{cc} / \mathrm{kg} / \mathrm{min}$; adults $60 \mathrm{cc} / \mathrm{kg} / \mathrm{min}$.) Usually centrifugal pump are preferred. Inlet and outlet line caliber should be selected to avoid either excessive suction or infusion pressure to avoid hemolysis.

The gas exchange material in membrane lung may be 


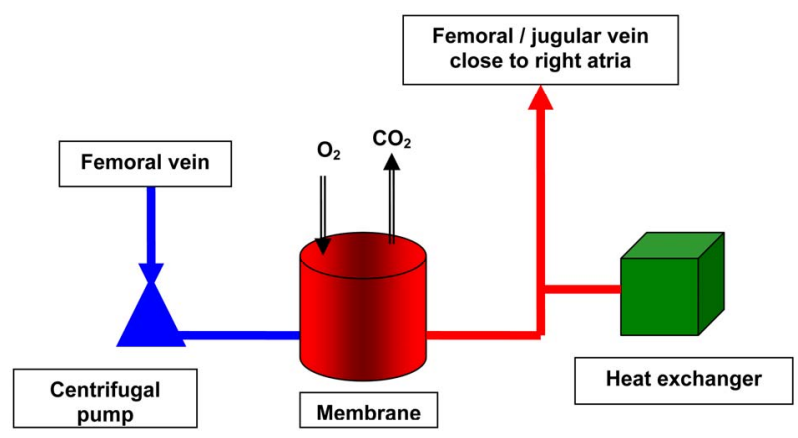

Figure 3. Schematic ECMO circuit.

solid silicone rubber, a microporous hollow-fibre (polypropylene), or a solid hollow-fibre (PMP, polymethyl pentene) membrane. Membrane surface area and mixing in the blood path determine the maximum oxygenation capacity (the rated flow) [19].

In venovenous mode, recirculation of infused blood may occur, raising the inlet saturation well above $75 \%$. In this situation the outlet-inlet $\mathrm{O}_{2}$ difference per unit of blood flow is decreased, and higher blood flow, cannula repositioning, increased patient volume or higher hematocrit are required to provide the desired amount of $\mathrm{O}_{2}$ delivery.

For most applications, the sweep gas will be $100 \%$ oxygen or carbogen $\left(5 \% \mathrm{CO}_{2}, 95 \% \mathrm{O}_{2}\right)$ at a flow rate equal to the blood flow rate $(1: 1)$. Increasing the sweep flow will increase $\mathrm{CO}_{2}$ clearance but will not affect oxygenation. Water vapor can condense in the membrane lung and may be cleared by intermittently increasing sweep gas flow to a higher flow.

Air or oxygen bubbles can pass through the membrane into the blood if the sweep gas pressure exceeds the blood pressure, or if the blood pressure is subatmospheric (this occurs when there is no blood flow or blood pressure, and blood drains from the membrane lung into the tubing by gravity, entraining air through the membrane lung). This is a specific problem with microporous hollow fibre devices but can also occur with Silicone or polymethyl-pentene lungs are due to minor defects which can allow air entrainment. Prevention is achieved by maintaining the blood side pressure higher than the gas side pressure. This is accomplished by including a pressure pop off valve or pressure servo regulation control in the sweep gas supply, and by keeping the membrane lung below the level of the patient, so that if the pump stops the risk of entraining air from the room will be minimized. Even with silicone and PMP lungs it is safest to maintain the membrane lung below the level of the patient [19].

\subsection{Running ECMO}

Ideally, the oxygenated blood would be closer to the right atrium. Thanks to a centrifugal pump, the blood is collected and fed to a membrane oxygenator. As for the lungs, the blood oxygenation (and removing $\mathrm{CO}_{2}$ ) depends on both the flow rate of blood there through (the circuit has a blood flow calculator that is displayed on a console) and also flow of oxygen-enriched air which sweeps the surface of the membrane. The blood is then reheated before being reinjected into the venous system [19].

Then assistance provides haematosis and ventilation may become even more protective (Table 1). Thus tidal volume delivered by the ventilator can be decreased below $6 \mathrm{ml} / \mathrm{kg}$ (down to 1 to $2 \mathrm{ml} / \mathrm{kg}$ !) respecting a plateau pressure of less than $28 \mathrm{~cm} \mathrm{H}_{2} \mathrm{O}$, while maintaining a high PEEP (10 to $15 \mathrm{~cm} \mathrm{H}_{2} \mathrm{O}$ ). These settings will protect healthy areas pending recovery of those affected by the inflammation. The auto worsening vicious circle of mechanical ventilation is thus broken.

ECMO is left in place the necessary time to get sufficient pulmonary function recovery. The theoretical duration of its use is ten days beyond which the membrane can be altered and becomes less effective. But the membrane can be changed by the perfusionist (extracorporeal circulation specialist nurse) if assistance should be continued.

Blood gas improvement, radiological and mechanical ventilation (evidenced by an increase in compliance) sign the beginning of normalization of pulmonary function. ECMO withdrawal is considered if the blood gas can be re-assured by the lungs while remaining in a profile of ultra protective mechanical ventilation settings. It takes place gradually with reduced flow rates to test the effectiveness of the single mechanical ventilation on oxygenation and purification of $\mathrm{CO}_{2}$.

\section{THE INTENSIVE CARE NURSE, GUARANTEE OF PROTECTIVE VENTILATION}

The patient care with ARDS under ECMO combines nursing related to heavy intensive treatment (immobility, sedation, enteral and parenteral nutrition), acute monitoring of very restrictive mechanical ventilation and ECMO. This explains why this nursing workload may require nurse staffing adaptation, allowing one nurse per patient.

\subsection{Monitoring Ventilation}

A key challenge in the nurse management is monitoring ventilation. To prevent baro-or-volo trauma, plateau pressure is monitored continuously to alert if it rises beyond $28 \mathrm{~cm}$ of water. This data can also assess the recovery of the lung: a decrease in the plateau pressure for a fixed tidal volume indicates an improved compliance, then a regression of inflammation, whatever the ventilator mode 
(Table 2).

\subsection{Avoiding Alveolar Derecruitment}

Recovery may be delayed by derecruitment episodes.

Some nursing expose to the fall of the PEEP like endotracheal aspirations, or disconnections of the respiratory circuit during aerosol delivery or mobilization of the patient [20]. To limit the risk, arrangements can be made (Table 3) as the installation of a closed aspiration system on the respiratory circuit that will allow to make the aspirations without disconnection [20]. For manipulations that require disconnection of the circuit, the endotracheal tube can be clamped few seconds; then PEEP effect is not lost. Similarly, for a good seal of the circuit, the tracheal balloon pressure should be checked several times a day. Finally, verifying the proper humidification of the circuit helps to protect lung as cold oxygen dries respiratory secretions that may cause mucus plugs.

\subsection{Monitoring ECMO}

ECMO, compensating the lungs, ensures highly protective ventilation, provided its optimal functioning is appropriately ensured by the nurse. Blood flow may be variable and should be controlled continuously. The effectiveness of extracorporeal membrane oxygenation depends on the blood flow that must be at least 2.5 liters/ minute. Below, the patient may not receive enough oxygenated blood and is exposed to hypoxia. In addition to adjusting the flow of the blood pump (tour/min), the performance depends on the ECMO circuit integrity (the lines are not to be bent or stuck in a fence!), and a sufficient blood volume (risk of flow rate decrease if there is not enough venous return to the pump). Finally, like any extracorporeal circuit, there is a risk of thrombosis

Table 2. Ventilator modes, settings and monitoring.

\begin{tabular}{|c|c|c|}
\hline & $\begin{array}{c}\text { Volume Controlled } \\
\text { ventilation }\end{array}$ & $\begin{array}{c}\text { Pressure Controlled } \\
\text { Ventilation }\end{array}$ \\
\hline Settings & $\begin{array}{c}\text { Respiratory rate } \\
\text { PEEP }^{*} \\
\text { Tidal volume }\end{array}$ & $\begin{array}{c}\text { Respiratory rate } \\
\text { PEEP }^{*} \\
\text { Insufflation } \\
\text { pressure }^{* *}\end{array}$ \\
\hline Monitoring & Plateau pressure & Tidal volume \\
\hline
\end{tabular}

*PEEP: Positive end expiratory pressure; ${ }^{* *}$ Insufflation pressure $=$ Plateau pressure.

Table 3. Preventing the derecruitment risk.

\begin{tabular}{|c|c|}
\hline & Principles \\
\hline Avoiding leakages & $\begin{array}{l}\text { 1) Closed aspiration system } \\
\text { 2) Endotracheal tube clamping if circuit } \\
\text { disconnection (aerosols, mobilization) } \\
\text { 3) Vigilance +++ in care }\end{array}$ \\
\hline
\end{tabular}

which would reduce the effectiveness of the membrane oxygenator, and therefore alters the patient's blood gas. The blood is anticoagulated (heparin), which requires close monitoring (ACT) (Table 4).

The performance of the combination of protective ventilation and ECMO is assessed on haematosis, already estimated by the nurse through cannula color: a dark red line corresponds to venous blood, low oxygened then the admission line. Conversely red line signs a well oxygenated blood, then the infusion line. Blood gas taken regularly allows adapting the settings of ECMO. If the blood flow rate is satisfactory, the $\mathrm{FiO}_{2}$ is increased (up to 1 if necessary) in cases of hypoxia, and the sweep gas rate is increased in case of hypercapnia [19].

After explantation, the nurse monitoring remains focused on mechanical ventilation with the same objectives of protective ventilation. When the situation is normalized, weaning from mechanical ventilation is started with the usual steps, including relief sedation and spontaneous ventilation as soon as possible. Even in this mode, lung protection criteria should be applied in particular to the tidal volume which must remain at a low level.

\section{CONCLUSION}

The emergence of serious diseases such as H1N1 that cause ARDS, has lead medical teams designed to take care of these patients to turn to alternative techniques of respiratory support like ECMO. These techniques require expertise developed through regular practice to be exploited optimally and safely. Indeed, a multidisciplinary team of intensivists, surgeons and perfusionists is mobilized during the implantation of the assistance. Logically, intensive care nurses taking care of these patients afterwards should be educated in order to guarantee appropriate monitoring and care. In addition to the usual intensive care unit patient, the intensive care nurse will have to integrate the operation of the machine, understanding ventilation requirements, to be able to provide early warning if the patient develops signs of worsening condition. So, naturally, the role of the nurse tends to evolve with technological developments, its role being close supervision of course, but also an ability to assess

Table 4. ECMO settings and monitoring.

\begin{tabular}{ccc}
\hline & Settings & Monitoring \\
\hline Blood flow & Tours/min & Flow L/min \\
Sweep gas & Air/ $\mathrm{O}_{2}$ mixture flow & $\begin{array}{c}\text { Color of cannulas } \\
\text { Blood gas } \\
\text { FiO }\end{array}$ \\
Anticoagualtion & Heparin & State of the membrane \\
\hline
\end{tabular}


the risks to which expert knowledge and a good understanding of the treatment plan are necessary.

\section{REFERENCES}

[1] Bernard, G.R., Artigas, A., Brigham, K.L., Carlet, J., Falke, K., Hudson, L., Lamy, M., Legall, J.R., Morris, A. and Spragg, R. (1994) The American European Consensus Conference on ARDS. Definitions, mechanisms, relevant outcomes, and clinical trial coordination. American Journal of Respiratory and Critical Care Medicine, 149, 818824.

[2] Ware, L.B. and Matthay, M.A. (2000) The acute respiratory distress syndrome. The New England Journal of Medicine, 342, 1334-1349. doi:10.1056/NEJM200005043421806

[3] Brun-Buisson, C., Minelli, C., Brun-Buisson, C., Bertolini, G., Brazzi, L., Pimentel, J., Lewandoski, K., Bion, J., Romand, J.A., Villar, J., Thorsteinsson, A., Damas, P., Armaganidis, F. and the ALIVE Study group (2004) Epidemiology and outcome of acute lung injury in European intensive care units. Results from the ALIVE study. Intensive Care Medicine, 30, 51-56. doi:10.1007/s00134-003-2136-X

[4] Webb, H.H. and Tierney, D.F. (1974) Experimental pulmonary edema due to intermittent positive pressure ventilation with high inflation pressures. American Review of Respiratory Disease, 110, 556-565.

[5] Dirkes, S., Dickinson, S. and Valentine, J. (1992) Acute respiratory failure and ECMO. Critical Care Nurse, 12, 39-47.

[6] Combes, A., Bacchetta, M., Brodie, D., Müller, T. and Pellegrino, V. (2012) Extracorporeal membrane oxygenation for respiratory failure in adults. Current Opinion in Critical Care, 18, 99-104.

[7] Crimi, E. and Slutsky, A.S. (2002) Inflammation and the acute respiratory distress syndrome. Best Practice \& Research Clinical Anaesthesiology, 18, 477-492. doi:10.1016/j.bpa.2003.12.007

[8] Herridge, M.S., Tansey, C.M., Matté, A., Tomlinson, G., Diaz-Granados, N., Cooper, A., Guest, C.B., Mazer, C.D., Mehta, S., Stewart, T.E., Kudlow, P., Cook, D., Slutsky, A.S. and Cheung, A.M. (2011) Functional disability 5 years after acute respiratory distress syndrome. The New England Journal of Medicine, 364, 1293-1304. doi:10.1056/NEJMoa1011802

[9] Brodie, D. and Bacchetta, M. (2011) Extracorporeal membrane oxygenation for ARDS in Adults. The New England Journal of Medicine, 365, 1905-1914. doi:10.1056/NEJMct1103720

[10] Papazian, L., Forel, J.-M., Gacouin, A., Penot-Ragon, C., Perrin, G., Loundou, A., Jaber, S., Arnal, J.-M., Perez, D., Seghboyan, J.-M., Constantin, J.-M., Courant, P., Lefrant, J.-Y., Guerin, C., Prat, G., Morange, S. and Roch, A. (2010) Neuromuscular blockers in early acute respiratory distress syndrome. The New England Journal of Medicine, 363, 1107-1116. doi:10.1056/NEJMoa1005372

[11] Boussarsar, M., Thierry, G., Jaber, S., Roudot-Thoraval,
F., Lemaire, F. and Brochard, L. (2004) Relationship between ventilatory settings and barotrauma in the ARDS. Intensive Care Medicine, 28, 406-413. doi:10.1007/s00134-001-1178-1

[12] Dreyfuss, D. and Saumon, G. (1998) Ventilator-induced lung injury: Lessons from experimental studies. American Journal of Respiratory and Critical Care Medicine, 157, 294-323.

[13] Briel, M., Meade, M., Mercat, A., Brower, R.G., Talmor, D., Walter, S.D., Slutsky, A.S., Pullenayegum, E., Zhou, Q., Cook, D., Brochard, L., Richard, J.C., Lamontagne, F., Bhatnagar, N., Stewart, T.E. and Guyatt, G. (2010) Higher vs lower positive end-expiratory pressure in patients with acute lung injury and acute respiratory distress syndrome. Systematic review and Meta-analysis. Journal of the American Medical Association, 303, 865-873. doi:10.1001/jama.2010.218

[14] Amato, M.B.P., Barbas, C.S.V., Medeiros, D.M., Magaldi, R.B., Schettino, G.P.P., Lorenzi-Filho, G., Kairalla, R.A., Deheinzelin, D., Munoz, C., Oliveira, R., Takagaki, T.Y. and Carvalho, C.R.R. (1998) Effect of a protective ventilation strategy on mortality in the ARDS. The New England Journal of Medicine, 338, 347-354. doi:10.1056/NEJM199802053380602

[15] The Acute Respiratory Distress Syndrome Network (2000) Ventilation with lower tidal volumes as compared with traditional tidal volumes for acute lung injury and the acute respiratory distress syndrome. The New England Journal of Medicine, 342, 1301-1308.

[16] Peek, G.J., Mugford, M., Tiruvoipati, R., Wilson, A., Allen, E., Thalanany, M.M., Hibbert, C.L., Truesdale, A., Clemens, F., Cooper, N., Firmin, R.K. and Elbourne, D. (2009) Efficacy and economic assessment of conventional ventilatory support versus extracorporeal membrane oxygenation for severe adult respiratory failure (CESAR): A multicentre randomized controlled trial. Lancet, 374, 1351-1363. doi:10.1016/S0140-6736(09)61069-2

[17] The Australia and New Zealand Extracorporeal Membrane Oxygenation (ANZ ECMO) Influenza Investigators (2009) Extracorporeal membrane oxygenation for 2009 influenza A (H1N1) acute respiratory distress syndrome. Journal of the American Medical Association, 302, 18881895. doi:10.1001/jama.2009.1535

[18] Kopp, R., Henzler, D., Dembinski, R. and Kuhlen, R. (2004) Extracorporeal membrane oxygenation by acute respiratory distress syndrome. Anaesthesist, 53, 168-174. doi:10.1007/s00101-003-0643-3

[19] ELSO Guidelines for Cardiopulmonary Extracorporeal Life Support Extracorporeal Life Support Organization, Version 1:1. Ann Arbor, April 2009.

http://www.elso.med.umich.edu

[20] Maggiore, S.M., Lellouche, F., Pigeot, J., Taille, S., Deye, N., Durrmeyer, X., Richard, J.-C., Mancebo, J., Lemaire, F. and Brochard, L. (2003) Prevention of endotracheal suctioning-induced alveolar derecruitment in acute lung injury. American Journal of Respiratory and Critical Care Medicine, 167, 1215-1224. doi:10.1164/rccm.200203-1950C 